\section{Monitoring asthma in children: what does BATMAN tell us?}

\author{
Louise Fleming ${ }^{1,2}$
}

The importance of monitoring asthma and adjusting treatment according to control is a fundamental part of asthma management and many studies have demonstrated the benefits of achieving good control. Numerous tools can be used, including spirometry, inflammometry, airway hyper-responsiveness and validated questionnaires of asthma control and asthma-related quality of life. In practice, the clinician uses a combination of some (or none!) of these. However, the evidence of the utility of most of these is lacking, particularly in children. Studies that have been carried out are hampered by a number of constraints: first, there is no gold standard for asthma control. The Global Initiative for Asthma (GINA) definition of controlled, partially controlled or uncontrolled is often used. ${ }^{1}$ This is a composite measure, including symptoms, exacerbations and lung function, which was developed for adults and has not been validated in children. It is not universally used to assess the usefulness of monitoring strategies and a variety of end points, including exacerbations, symptomfree days (SFD), inhaled corticosteroid (ICS) dose and $\mathrm{FEV}_{1}$, have been reported. Second, studies tend to evaluate each measure in isolation: lung function or measurement of exhaled nitric oxide (FeNO) versus standard care and so on and there is limited evidence as to how the various components of control should be integrated. Third, the term 'standard care' is also open to much interpretation. The BATMAN study reported in Thorax compares two different management strategies with 'standard care'. ${ }^{2}$ In this study, standard care is based on the Asthma Control Test (ACT) ${ }^{3}$ score (or Childhood Asthma Control Test (C-ACT) ${ }^{4}$ for younger children) measured every 4 months at routine clinic visits. The two alternative strategies are ACT/C-ACT measured monthly and the addition of FeNO

\footnotetext{
${ }^{1}$ National Heart and Lung Institute, Imperial College, London, UK; ${ }^{2}$ Royal Brompton and Harefield NHS Foundation Trust, London, UK
}

Correspondence to Dr Louise Fleming, Department of Paediatric Respiratory Medicine, Royal Brompton Hospital, Sydney Street, London SW3 6NP, UK; I. fleming@imperial.ac.uk to the 4-monthly visits. While use of a symptom score to guide treatment changes provides standardisation in a study involving multiple centres and paediatricians, it is not, as yet, 'usual care' for most clinicians to change treatment on the basis of ACT/C-ACT alone and most, at the very least, would also include recent asthma attacks. Although ACT and C-ACT relate well to the GINA definitions of asthma control, the commonly used cut-off points underestimate the proportion of children with uncontrolled asthma. ${ }^{5}$ There is little evidence at present that ACT/C-ACT used alone is more useful than usual care for monitoring asthma in children. The BATMAN study does not help in this respect as these questionnaires were used in all three monitoring strategies. It would have been useful to have a true 'usual care' group as a comparator. However, that was not the primary aim of the study which instead was to assess whether more frequent assessments with ACT/C-ACT (monthly) or the measurement of FeNO (4-monthly) led to a reduction in SFD. The addition of FeNO resulted in a small increase in ACT/C-ACT score, which was less than the minimally important difference (MID) previously published by the same authors ${ }^{6}$ and much less than the widely accepted MID of $3 .^{7}$ Most of those enrolled had high ACT scores at baseline and therefore it is unsurprising that the primary end point (SFD) was not significantly different between the groups as there was little room for improvement. However, there was some benefit for those in the monthly ACT/C-ACT group in terms of ICS dose. In part, this was due to the better ACT and Paediatric Asthma Quality of life Questionnaire (PAQLQ) at baseline in this group compared with the other two groups. Improved adherence due to increased contact with the study team is another plausible explanation, although one might expect to see a fall in the level of FeNO in this group, whereas in fact the FeNO significantly increased. More likely, the frequent contact gave multiple opportunities to change treatment and tailor ICS dose to the level of control, in most case leading to dose reduction. This echoes the findings of the FeNO management study by De Jongste et $a l^{8}$ Children recorded symptoms at home and were contacted every 3 weeks. The intervention group also measured FeNO daily. There was no additional benefit from adding FeNO to the monitoring strategy; however, what was striking were improvements in asthma control seen in both groups and the reduction in ICS dose.

Most guidelines focus on the type of monitoring and statements about frequency are vague-anything from monthly to an annual review. The draft National Institute of Health and Care Excellence (NICE) guidance on diagnosing and monitoring asthma provides a commendably extensive review of the literature on monitoring strategies but does not address the question as to how often patients should be monitored. ${ }^{9}$ A recent European Respiratory Society (ERS) Task Force on monitoring asthma in children concluded that the frequency of follow-up should increase in proportion to asthma severity. ${ }^{10}$ As a general rule, the worse the asthma control, the more frequently the patient is seen. However, as evidenced by the BATMAN study, there may also be merit in frequently monitoring those with good control. Health systems across Europe are already overburdened and the prospect of more frequent routine appointments is unlikely to be welcomed; however, this could be offset against potential reductions in more costly unscheduled healthcare visits for those with poor control and lower treatment costs for those who are well controlled. Consultations do not necessarily need to take place in conventional healthcare settings. Most patients with asthma collect regular prescriptions which are dispensed by a pharmacist. The Finland experience has demonstrated the merits of these opportunistic interactions. ${ }^{11}$ Furthermore, as in the BATMAN study, interaction with a healthcare professional does not need to be face to face and the web-based monitoring used in this study is likely to be cost effective (the cost analysis is awaited). The results of telemonitoring studies have hitherto been disappointing as evidenced by the 2011 Cochrane review. ${ }^{12}$ However, the variety of methods used (and again the frequency of contact) makes it difficult to draw meaningful conclusions. Such interventions need to be tailored to the target population. Technology and channels of communication have continued to change rapidly, particularly over recent years and all the studies included in the Cochrane review were published over 6 years ago. Most adolescents have their 


\section{Editorial}

own Smartphones, something of a misnomer as the telephone part of which is the least used function. For many, email is almost obsolete with instant messaging the preferred mode of communication and anything beyond 140 characters unlikely to be read.

So what can we learn from BATMAN? Although the primary outcome was negative, the study illustrates that finding ways to effectively communicate with young people and use advances in technology to make healthcare interactions meaningful is likely a more important issue than what monitoring tool is actually used. Gotham city is still in trouble: send for ROBIN!

Competing interests None declared.

Provenance and peer review Commissioned; internally peer reviewed.

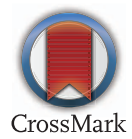

To cite Fleming L. Thorax 2015;70:517-518.

Published Online First 2 May 2015

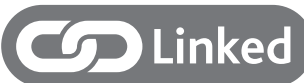

- http://dx.doi.org/10.1136/thoraxjnl-2014-206161

Thorax 2015:70:517-518.

doi:10.1136/thoraxjn-2015-206898

\section{REFERENCES}

1 Global Initiative for Asthma: Global strategy for asthma management and prevention 2014. http:// www.ginasthma.org (accessed Oct 2014).

2 Voorend-van Bergen S, Vaessen-Verberne AA, Brackel HJ, et al. Monitoring strategies in children with asthma: a randomised controlled trial. Thorax 2015;70:543-50.

3 Nathan RA, Sorkness CA, Kosinski M, et al. Development of the asthma control test: a survey for assessing asthma control. J Allergy Clin Immunol 2004;113:59-65.

4 Liu AH, Zeiger R, Sorkness C, et al. Development and cross-sectional validation of the Childhood Asthma Control Test. J Allergy Clin Immunol 2007;119:817-25.
5 Koolen BB, Pijnenburg MW, Brackel HJ, et al. Comparing Global Initiative for Asthma (GINA) criteria with the Childhood Asthma Control Test (C-ACT) and Asthma Control Test (ACT). Eur Respir.J 2011;38:561-6.

6 Voorend-van BS, Vaessen-Verberne AA, Landstra AM, et al. Monitoring childhood asthma: web-based diaries and the asthma control test. J Allergy Clin Immunol 2014;133:1599-605.

7 Schatz M, Kosinski M, Yarlas AS, et al. The minimally important difference of the Asthma Control Test. J Allergy Clin Immunol 2009;124:719-23.

8 De Jongste JC, Carraro S, Hop WC, et al. Daily telemonitoring of exhaled nitric oxide and symptoms in the treatment of childhood asthma. Am J Respir Crit Care Med 2009;179:93-7.

9 Asthma Diagnosis and Monitoring; NICE draft clinical guideline. 2015. https://www.nice.org.uk/guidance/ indevelopment/gid-cgwave0640

10 Pijnenburg MW, Baraldi E, Brand PL, et al. Monitoring asthma in children. Eur Respir J 2015;45:906-25.

11 Haahtela T, Tuomisto LE, Pietinalho A, et al. A 10 year asthma programme in Finland: major change for the better. Thorax 2006;61:663-70.

12 McLean S, Chandler D, Nurmatov U, et al. Telehealthcare for asthma: a Cochrane review. CMAJ 2011;183:E733-42. 